\title{
Educational and digital tools as factors of service quality increase in Thailand 4.0 era (the case of Suvarnabhumi Airport, Bangkok)
}

\author{
Kanittha Charernnit ${ }^{1, *}$ \\ ${ }^{1}$ International College, Suan Sunandha Rajabhat University, Bangkok, Thailand
}

\begin{abstract}
Currently, Thailand implemented the project Thailand 4.0 essentially highlighted on better performance on human resource as well as an information technology management. However, service quality is the key to create the business differentiation as well as to elevate a superior level of market competitiveness. The aviation industry is one of the most intense competitive industry, therefore, passengers' satisfaction on airport service quality and its' efficient facility management is the most important factor that can create business differentiation and influenced a sustainable industry accordingly. This paper seeks to investigate the (1) factors that affect service quality and (2) passengers' satisfaction of Suvarnabhumi airport in Thailand 4.0 era. Where the concept of Importance-Performance Analysis (IPA) has been implemented in this research, the results show that passenger's expectation on service quality was higher than the services that passengers received in many areas. However, from 150 questionnaires that have been released, the research results indicated that most of the respondents placed the highest satisfaction on the quality of internet and wireless connectivity service as the top priority at Suvarnabhumi Airport, whereas the lowest satisfaction is placed on the service quality of an immigration process where the effectiveness of human resources management is the key element affecting the service quality. Moreover, there is a recommendation on the self-check-in-counter and the processing of this service that needs to be modernized and promote passengers to use this technology widely. Hence, to enhance the airport service quality toward Thailand 4.0, the technology should be taken into account at every level to increase passengers' satisfaction throughout the passenger's arrival, departure and transit process accordingly.
\end{abstract}

\section{Introduction}

Recently, Thailand government has implemented this strategic model to develop conceptual idea to be ready for the upcoming future. The important factor to make Thailand Economy 4.0 strive to success is to deliver the knowledge to the society, to enable the people to be aware, to realize the value and to participate in the development and educating the people in Thai society inevitably through training and education.

\footnotetext{
* Corresponding author: kanittha.ch@ssru.ac.th
} 
The Thailand 4.0 concept, has been mentioned by many experts - Ayuwattanachai, mentioned that Thailand's National policy has shifted from 1.0 to Thailand 4.0 [1]. It can be explained that, the development model of 1.0 focused on agricultural, while 2.0 stressed on light industrial for instance weaving, canned food, drugs and medical equipment. Then the Thailand 3.0 development model emphasized on heavy industrial, and exportation of goods such as machinery.

Finally, for Thailand 4.0, it is highlighted on the development model that driving the country's economy by innovation, or technology adaptation. [2] said that if any country has a clear strategic development plan based on a strong economy, good infrastructure, abundant of natural resources and a potential tourism personnel, then there will be an important factor that will help drive the country to develop tourism growth.

The opening of Suvarnabhumi Airport has significantly contributed to the dynamism that drives forward the national logistic system [3]. With a Free Zone cargo management, freight transportation and cargo management at Suvarnabhumi Airport will be quicker, more convenience and efficiency. As a result, it has boosted growth in cargo transportation through Suvarnabhumi, increasing Thailand's competitive potential in the air transport industry. For regional airports, AOT will swiftly develop strategies that support logistics and tourism while expanding height routing network to cover all corners of the globe. AOT will establish Thailand as a logistic hub in air freight to GMS countries and those in South Asia.

For further information, The GMS countries referred to The Greater Mekong Subregion comprises Cambodia, the People's Republic of China (specifically Yunnan Province and Guangxi Zhuang Autonomous Region), Lao People's Democratic Republic, Myanmar, Thailand, and Viet Nam.Meanwhile, Phuket and Chiang Mai International Airports will be developed to be the regional gateways of country [15].

The Airports of Thailand Public Company Limited (AOT), is a leader of Thailand's airport business operator and has a long history of operations. Its main business lines are managing, operating and developing airports in Thailand [3].

Presently, AOT has 6 international airports under responsibility [3]: Don Mueang, Phuket, Chiang Mai, Hat Yai, Chiang Rai and Suvarnabhumi, all of which accommodate both domestic and international heights. Suvarnabhumi Airport serves as the main airport replacing Don Mueang International Airport, which was unable to accommodate the overwhelming air traffic growth.

At an initial stage, Suvarnabhumi Airport has a capacity to accommodate up to 45 million passengers and 3 million tons of cargo per year. Within a single hour, the airport can operate up to 76 Flights. AOT's main revenue derives from: (a) aeronautical revenue consisting of landing charge, parking charge, passenger service charge and aircraft service charge, and (b) non- aeronautical revenue consisting of concession revenue, office and real property rents and service revenues.

In 2018, air traffics ended with growth in aircraft movements, passengers and air cargo volume. Although the growth rate declined from previous years due to many airports almost reached its operating capacities. Airlines still increased their flights and switched some services from Domestic to International in respond to an increased in air travel demand especially from China and India. As a result, the number of aircraft movements andpassenger's volume at 6 AOT's airports grew by $6.54 \%$ and $5.53 \%$ respectively. Aircraft movements increased from 833,084 to 887,602 flights. Number of passengers increased from 133.12 to 140.47 million. (see table 1). 
Table 1. AOT Air Traffic Year 2018 (Adapted from AOT 2018 Annual Report, Airports of Thailand Public Company Limited).

\begin{tabular}{|l|c|c|c|c|c|c|}
\hline \multicolumn{1}{|c|}{ Airport } & $\begin{array}{c}\text { Interna- } \\
\text { tional }\end{array}$ & $\begin{array}{c}\text { \% } \\
\text { Change }\end{array}$ & Domestic & $\begin{array}{c}\text { \% } \\
\text { Change }\end{array}$ & Total & $\begin{array}{c}\text { \% } \\
\text { Change }\end{array}$ \\
\hline Aircraft movement (Flights) \\
\hline Suvarnabhumi & 281.879 & $6.66 \%$ & 87.597 & $1.59 \%$ & 369.476 & $5.41 \%$ \\
\hline Don Mueang & 97.555 & $10.52 \%$ & 174.806 & $3.75 \%$ & 272.361 & $6.08 \%$ \\
\hline Chiang Mai & 21.690 & $16.73 \%$ & 56.520 & $5.82 \%$ & 78.210 & $8.63 \%$ \\
\hline Hat Yai & 3.314 & $51.05 \%$ & 25.889 & $-7.12 \%$ & 29.203 & $-2.87 \%$ \\
\hline Phuket & 63.766 & $19.94 \%$ & 54.514 & $3.00 \%$ & 118.280 & $11.49 \%$ \\
\hline Chiang Rai & 1.920 & $91.24 \%$ & 18.152 & $8.98 \%$ & 20.072 & $13.65 \%$ \\
\hline Total 6 airports & 470.124 & $9.97 \%$ & 417.478 & $2.93 \%$ & 887.602 & $6.54 \%$ \\
\hline Passengers volume $($ Persons) \\
\hline Suvarnabhumi & 51.507 .176 & $4.01 \%$ & 11.871 .901 & $4.71 \%$ & 63.379 .077 & $4.14 \%$ \\
\hline Don Mueang & 15.978 .892 & $11.29 \%$ & 24.779 .256 & $3.50 \%$ & 40.758 .148 & $6.42 \%$ \\
\hline Chiang Mai & 2.674 .651 & $16.35 \%$ & 8.315 .218 & $4.84 \%$ & 10.989 .869 & $7.42 \%$ \\
\hline Hat Yai & 352.763 & $24.26 \%$ & 3.903 .334 & $-4.41 \%$ & 4.256 .107 & $-2.55 \%$ \\
\hline Phuket & 10.403 .631 & $13.13 \%$ & 7.817 .894 & $2.08 \%$ & 18.221 .525 & $8.11 \%$ \\
\hline Chiang Rai & 228.804 & $91.00 \%$ & 2.638 .485 & $10.69 \%$ & 2.867 .289 & $14.54 \%$ \\
\hline Total 6 airports & 81.145 .917 & $7.08 \%$ & 59.326 .098 & $3.47 \%$ & 140.472 .015 & $5.53 \%$ \\
\hline
\end{tabular}

In 2018, [3] 110 airlines provided international scheduled services at Suvarnabhumi Airport, with 51.23 million of international passengers. AOT's airports accommodated 140.47 million passengers with $5.53 \%$ growth. The majorities of passenger traffic were in both Bangkok airports, which consisted of Suvarnabhumi and Don Mueang. The major regional airport such as Chiang Mai and Phuket also experienced high growth due to high volume of international tourists travelled with local low-cost airlines and Chinese airlines. Hence, the number of passengers over the past decade has grown for $11.22 \%$ with compound average annual growth rate.

From 140.47 million passengers across AOT's 6 airports in 2018, 81.15 million were international and 59.33 million were domestic passengers, with $7.08 \%$ and $3.47 \%$ increased respectively. The proportion between international and domestic movements was 57.77 to 42.23, slightly changed from 56.93 to 43.07 of last year.

For international passengers, $63.47 \%$ travelled through Suvarnabhumi Airport, whereas $41.77 \%$ of domestic passengers travelled through Don Mueang International Airport.

Suvarnabhumi Airport of Thailand is considered one of the best three locations as a main hub of aviation in Southeast Asia because Thailand has a good geographical location, good facility and technology in the airport. Whereas, Changi Airport in Singapore, is considered one of the busiest airports for international traffic, which served over 65.6 million passengers in 2018 and 68.3 million in 2019 respectively [4]. While, Suvarnabhumi airport served a bit lower when compared to Changi Airport at 51.5 million passengers in 2018.

Changi Airport has created passenger solution of travelling and create a signature experiences that redefine passengers for generations to visit. Changi Airport has strengthened its competitive airport with the implementation of technology which enable more passengers to visit. In terms of technology and services, Suvarnabhumi Airport, is behind Changi Airport as Suvarnabhumi Airport has not yet implement the tools and applications ineach service point, especially during the congested hours of each day on departure and arrival procedures it creates a big congestion in each area, which somehow makes passengers disappointing in the service quality that has been offered by the airport.

Thus, this study aims to access thefactors that affect service quality and the quality of services perceived bypassengers in Suvarnabhumi airport. This study carries out and 
investigation of the efficiency of technology on the self-check-in counter. Moreover, to conclude that the service quality dimension is interrelated and the important of technology and human resource management should be recognized.

This study is to investigate the digitalization management in service quality of Suvarnabhumi Airport in Thailand 4.0 era, and the passenger's satisfaction toward the service quality of Suvarnabhumi Airportespecially technology of the self-check-in counter servicein order to recommend the solutions andadvance technology in Suvarnabhumi Airport accordingly.

\section{Research Methodology}

The respondents of this survey were 150 tourists who visiting Thailand in October 2019. The data was collected by using a questionnaire (Questionnaire) as a tool in this study. The questionnaires were analyzed by using the Taro Yamane (Taro Yamane) formula and the statistic instruments that the researcher used to analyze the hypothesis is Chi-Square Test, Independent Sample T-Test and the ANOVA (Analysis of variance) which were analyzed by using the software program to process the data.

The measurement and management of passengers' satisfaction has become a key issue in the last decade. Airports must thoroughly understand the needs of their passengers and design products and services that meet and exceed passengers' expectations. In this research paper, the importance-performance analysis (IPA) is a used as a tool to analyze the data and passengers' satisfaction. Many researchers know the IPA tools and is widely used as an analytical technique that yields prescriptions for the management of customer satisfaction. IPA is a two-dimensional grid based on customer perceived importance of service attributes and attribute performance. Depending on the interplay of these two dimensions, four strategies can be derived.

The concept of Importance-Performance Analysis (IPA) has been implemented in this research as the main concept of IPA is to evaluate an airport service quality with the airport operational which is widely used within hospitality industry.

[5] has proposed the IPA evaluation matrix which is a tools to analyze the customer satisfaction and the interpretation could be analyzed as follows: I: Need an improvement, II: Keep up the good practice, III: Low Priority or Not important, IV: Possible over kill or an organization waste their cost for not an important issue.(see Figure 1)

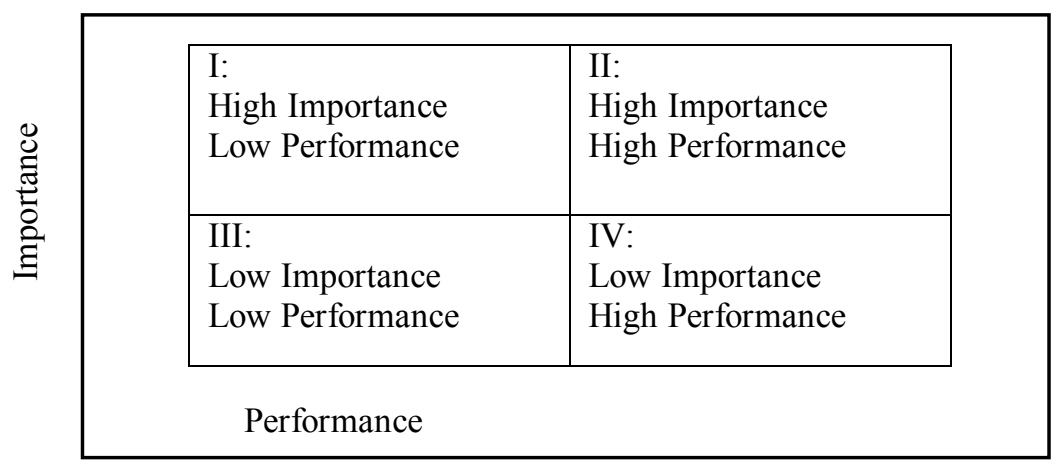

Fig. 1. Importance-Performance Analysis Matrix (IPA).

Service Quality: is defined as atheory model of the quality based on the result of gaps between people's expectations and their conception of service performance. 
International Airport: is defined as an airport typically provided with many facilities to handle international flights to and from other countries.

Airport Service Quality: is defined as passengers' attitude of services scope which provided by airport industry to satisfypassengers 'needs, wants and how their needs could be met.

Importance-Performance Analysis (IPA): is defined as a mechanism used for positioning a product or service with theirperformance evaluation and its importance to the customer.

\section{Research Literature Review}

Airport passengers can be categorized into many groups such as departing, arriving and transiting passenger, on the other hand, airport industry aim to serve passengers toward various expectation, and of course, it is very difficult to satisfy everybody. Therefore, to emphasis on customers' satisfaction is necessary in the dynamic competitive edge, especially, the level of segmentation was increased to serve various groups of passengers in which can be classified by passengers' behaviors, expectations and purpose of travelling accordingly.Airport quality service contributions must involve in technology and innovation particularly in fields related to Thailand's competitive edges and ability to deliver what digital - age technology which should meets passengers' need, behavior and must take place rapidly to enable Thai aviation industry to the new era, not just global-level but also for a sustainable competitiveness.

In recent years, there have been many studies about the concept of service,for example, [5] has stated the relationship of the airport infrastructure and airport service quality that, if airport infrastructure cannot accommodate to all services performances, airport service quality will be operated at a low level which could influenced to the negative perception of visitors as well as, when the service performance of the airport is at the low level, the perception of passenger towards the airport service quality will decline accordingly

Moreover, [5] stated in his paper about Passenger traffic at Kaohsiung International Airport in Taiwan has seen a steady decline in the past few years due to several effects, including the establishment of the Taiwan High Speed Rail, and industry moving abroad. Because economic conditions have improved to some degree, and the Taiwanese government has permitted Chinese tourists to visit Taiwan and has allowed cross-strait direct flights, passengers are increasing. Therefore, the airport's priority should be promoting its service quality and environment. His study analyzed the importance and satisfaction of domestic and international tourists using questionnaires, and further applied an importance-performance analysis (IPA) to assess priority services that need improvement and to provide appropriate advice.

The results showed that the priority services that must be improved comprise ground transportation, complaint handling, health center, speed of baggage claim, and comfort of the terminal.

Furthermore, the study from [6] about the influence of service quality has received limited attention in the context of airport research. This study investigates whether airport service quality is related to airport and destination choice. Specifically, the study examines the relationship between airport service quality, passenger satisfaction, and behavioral intentions including airport reuse and destination revisit. The sample consists of departure passengers in major Australian airports. The results confirm that overall airport service quality is significantly related to airport reuse and destination revisit. Passenger satisfaction and reuse airport exert significant mediation effects between airport service quality and intended outcome variables. Discussion and implications of these findings conclude this paper. 
[7] study the relationships among customer satisfaction, service quality and perceived value. These variables are increasingly recognized as being sources of competitive advantage. However, little empirical research has been conducted to examine these variables simultaneously and their relationships with post-purchase behavior. Jackie's paper was designed to develop an understanding of the relationships among these variables and their influence on post purchase behavior.

An integrative model was developed and tested using data collected from customers in the restaurant industry. The results reveal that customer satisfaction and perceived value significantly influence post-purchase behavior.

Moreover, [8] conduct a research on service quality, perceived value and customer satisfaction which are high interest to marketers. Jackie's research examined the crucial role of these variables that shaping post-purchase behavior within the context of restaurant industry. Customer satisfaction was found to be more strongly correlated with perceived performance than disconfirmation. In addition, the results revealed that customer satisfaction had the strongest effect on behavioral intentions, followed by perceived value. The effect of service quality on behavioral intentions was mediated through customer satisfaction.

The concept of Customer-Perceived Value (CPV) [9] has become a matter of increasing concern in marketing literature. However, there are few empirical studies that attempt to examine the notion of it. Filling this gap, this study provides a conceptual as well as empirical investigation of $\mathrm{CPV}$ as a formative construct and also offers an insight regarding the role of CPV in influencing, through satisfaction and loyalty, the behavioral intentions of word of mouth, repurchase intention and cross-buying. Furthermore, the potential moderating role of social pressure in the relationship between satisfaction and loyalty is also examined. The results suggest that delivering superior customer value enables a firm to achieve favorably behavioral intentions. Implications for practice, study limitations and future research are discussed.

[10] proposes to develop a service quality model, based on test of a sample of business executives, which describes how the quality of services is perceived by customers. Marketing implications, in which functional quality is a very important dimension of a perceived service. He concludes that quality dimensions are interrelated and that the importance of image should be recognized.

The term "service quality" is frequently used by both academician and practitioners. However, it is never defined in a way which could guide management decision.

[11] stated that service firms have to develop the quality of their services to be able to compete successfully in the future and that will be meaningless, unless one can 1) define how service quality is perceived by the consumers, and 2) determine in what way service quality is influenced.

Moreover, he developed a service quality model and explained that the quality of the service is dependent on two variables: expected service and perceived service. Therefore, in a service quality model we need to know the resources and activities, under the control and outside the immediate control of the firm that have an impact on these variables. The service quality model is shown in table 4 above.

[12] have suggested that the perceived performance of a product can be divided into two sub-process: namely, instrumental performance and expressive performance. In a service context, as an airline passenger's contacts with the employees of the company, physical and technical resources, such as in-checking desks, the plane itself, seats, meals and the passenger's contacts with other passengers.

The passenger's interactions with such human and non-human resources during the preflight, in-flight, and post-flight, production process will certainly have an effect on 
passengers' evaluations of the service, and on the service,passengers perceive and has received.

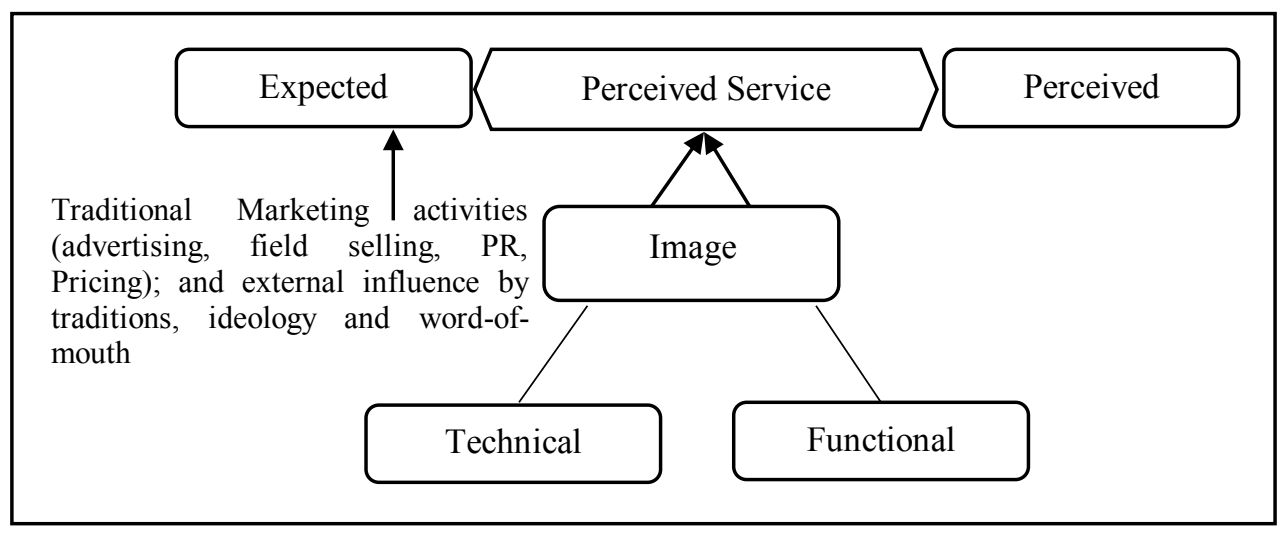

Fig. 2. The service quality model (adapted from $[11,12]$.

The logic goes on, [13] said that satisfaction is the most important tool to the tourist destination marketing. Furthermore, tourist's satisfaction is generally recognized as the most important factor to increase tourism destination loyalty. High level of tourists' satisfaction links to a high tourists' level of loyalty as the tourists are more likely to revisit the destination.

However, in developing airline industry and the airport service in order to increase a revisiting number of passengers, there are many factors that passengers will consider in revisiting Thailand for their vacation next time and use Suvarnabhumi airport as their port. That means airport should implement technology friendly service at the airport which passengers can access and experiencing the best services and experiencing the conveniences during their visit or transit.

\section{Research Results}

General information of respondents, the research results indicated that most of the sampling was female at 62.79 percent, age between 21-30 years old at 35.14 percent. Most of the sampling purpose of travelling is for vacation on their holiday. Referring to [14] paper on the Importance-performance analysis in airline service quality: a case study of legacy airlines in Thailand stated that the use of IPA technique to evaluate Thailand' legacy airline service attributes both ground services and in-flight services on domestic flights. Thai Airways International and Bangkok Airways performed a good job and should maintain the service quality and the passengers are satisfied with the services they received.

The research results revealed that the respondents placed the high satisfaction on internet and wireless connectivity service followed by efficiency of immigration staff and airport authority staff as well as easy connection with the next flight as the top three priority at Suvarnabhumi Airport. However, the respondents had the lowest satisfaction level for the attribute of self-check-in counter because this function does not indicate about the information of how to use in various languages which make passengers perceive this service as low level and not satisfy with the technology. Most passengers still need an assistant to ask and to show them of how to use the self-check-in service counter.

That is why this service has to be more on the information and technology friendly. The perceived service, on the other hand, is the result of the passenger's perception of the service itself.The previous experience with a service also influences the expectations of a 
passengers. The analysis also indicated that airport service quality has a positive influence on passenger behavior through value, satisfaction, and airport image.

The analysis reveals that airport service quality influences passengers' motive and the intention to recommend the airport to other passengers indirectly by means of value, satisfaction, and airport image. This result implies that if passengers think that they got high value from the airport services they received, they are more likely to be satisfied, to use the airport again, and to recommend the airport to other passengers. This result also indicated that passengers who has a positive overall impression of the airport are more likely to use the airport again and recommend the airport toothers.

\section{Conclusions and Recommendations}

As an airport serves as a first point to enter Thailand, its facilities and appearance could influence the satisfaction of a visitors. Due to an excessive number of tourists has visited Thailand for many years, airport activities and facilities have to be effective in terms of its service to encourage visitors to spend their time efficiently and also creates an impression on the facilities as well as an impression on the services staff respectively.

To increase commercial revenue and position to be the hub in Southeast Asia, Suvarnabhumi airport need to create a new stream of technology and innovation that connect all IT systems in the airport in form of an application that will facilitate passengers for the airport quality services. The IT system and application should connect with the related industry and connect with local tourist destinations.

Today, it is broadly known that airline industry plays an important role in economic development of many countries. However, the major aspect that was considered is the services among business that became the key to elevate and differentiate the competitive provision of business standard, not only in the hospitality industry but also in other organization. Quality and service has become essential as a tool to increase service standard and increase passenger's satisfaction. The relationship between the service quality and customer satisfaction is crystal clear in terms of increasing the competitive advantage and a sustainable business operation especially in the hospitality industry.

Finally, this study has some limitation which is the cooperation from the departure passengers as they are more concerning on their baggage check-in, the complexity of the self-check-in counter service, the technology that they are not get used to which can create the frustration for passenger as well as the limited time concerning on their departure, therefore some passengers may refuse to answer or fill in the questionnaires respectively.

\section{References}

1. K. Ayuwattanachai, $1.0+4.0$ new equation agriculture + corporate social responsibility (2017) www.posttoday.com

2. C. Tagenggsak, Quality of ecotourism development in the northeast region (Nakhon Ratchasima, Suranaree University of Technology. Nakhon Ratchasima, 2013)

3. Annual Report, Airports of Thailand Public Company Limited (Airports of Thailand Public Company Limited (AOT), 2018)

4. O. Decha, The EUrASEANs: Journal on Global Socio-Economic Dynamics 5(18), 6578 (2019)

5. C.C. Chao, H.C. Lin, C.Y. Chen, J. of the Eastern Asia Society for Transportation Studies 184 (2018)

6. C. Prentice, M. Kadan, J. of Retailing and Consumer Services 47, 40-48 (2019) 
7. L. Jackie, M. Tam, J. of Marketing Management 20(7-8), 897-917 (2004)

8. L. Jackie, M. Tarn, J. of Hospitality \& Leisure Marketing 6(4), 31-43 (1999)

9. P. Spiros et al., J. of Relationship Marketing 6(1), 63-87 (2007)

10. C. Grönroos, European Journal of Marketing 18(4) (1984)

11. C. Grönroos, Service management and marketing: managing the moments of truth in service competition (Lexington Books, Lexington, 1990)

12. A. Privara, Transnational Marketing Journal 7(1), 59-72 (2019)

13. M. Kozak, M. Rimington, J. of Travel Research 19(6), 260-269 (2010)

14. K. Kankaew, SDU Research Journal 11(3), 83-96 (2019)

15. A. Privara, Geographical Journal 71(2), 161-180 (2019) 